\title{
Are patients more adherent to newer drugs?
}

\author{
Katharina E. Blankart ${ }^{1,2,3}$ (D) Frank R. Lichtenberg ${ }^{1,4}$
}

Received: 27 August 2019 / Accepted: 8 July 2020 / Published online: 8 August 2020

(C) The Author(s) 2020

\begin{abstract}
The annual preventable cost from non-adherence in the US health care system amounts to $\$ 100$ billion. While the relationship between adherence and the health system, the condition, patient characteristics and socioeconomic factors are established, the role of the heterogeneous productivity of drug treatment remains ambiguous. In this study, we perform cross-sectional retrospective analyses to study whether patients who use newer drugs are more adherent to pharmacotherapy than patients using older drugs within the same therapeutic class, accounting for unobserved heterogeneity at the individual level (e.g. healthy adherer bias). We use US Marketscan commercial claims and encounters data for 2008-2013 on patients initiating therapy for five chronic conditions. Productivity is captured by a drug's earliest Food and Drug Administration (FDA) approval year ("drug vintage") and by FDA" therapeutic potential" designation. We control for situational factors as promotional activity, copayments and distribution channel. A 10-year increase in mean drug vintage is associated with a 2.5 percentage-point increase in adherence. FDA priority status, promotional activity and the share of mail-order prescription fills positively influenced adherence, while co-payments had a negative effect. Newer drugs not only may be more effective in terms of clinical benefits, on average. They provide means to ease drug therapy to increase adherence levels as one component of drug quality, a notion physicians and pharmacy benefit managers should be aware of.
\end{abstract}

Keywords Medicines possession ratio $\cdot$ Innovation $\cdot$ Vintage $\cdot$ Promotion $\cdot$ Productivity in health care

JEL classification I12 Health Behaviour · L65 Industry Studies: Biotechnology $\cdot$ C31 Cross Sectional Models

\section{Highlights}

- We perform comparisons within patients to analyze the role of drug quality in medication adherence

- We designed an integer linear program that can only be solved for small instances.

- We consider co-payments, promotion and patient heterogeneity as additional factors.

Electronic supplementary material The online version of this article (https://doi.org/10.1007/s10729-020-09513-5) contains supplementary material, which is available to authorized users.

\section{Katharina E. Blankart}

katharina.blankart@uni-due.de

Columbia Business School, Columbia University, New York, NY, USA

2 Present address: Faculty of Economics and Business Administration, University of Duisburg-Essen and CINCH - Health Economics Research Center, Campus Essen, Berliner Platz 6-8, 45127 Essen, Germany
- We use the concept of vintage as measured by the US Food and Drug Administration's year of market approval as an indicator of a drug's average quality; later-vintage drugs are hypothesized to have higher average quality than earlier-vintage drugs.

- Prescribers and pharmacy benefit managers should be aware that patients tend to be more adher-ent to newer drugs within a therapeutic class when making prescription choices.

3 Hamburg Center for Health Economics, University of Hamburg, Hamburg, Germany

4 National Bureau of Economic Research, Cambridge, MA, USA 


\section{Introduction}

In chronic diseases, biomedical innovation has been shown to contribute to improving health outcomes of populations [1]. Almost $90 \%$ of private biomedical R\&D is performed by biopharmaceutical companies [2], and government-funded R\&D also plays an important role in drug development [3]. Successful drug therapy not only depends on the type of drug agent used. Equally if not more important is whether patients use the medicines prescribed as advised. Outside clinical trials, low adherence is widespread [4-6]. Moreover, nonadherence is recognized as a significant source of waste. The annual preventable cost from non-adherence in the US health care system has been estimated at around $\$ 100$ billion [7, 8]. Non-adherence accounts for about half of the potentially avoidable cost of inappropriate medication usage.

Adherence levels may be improved by interventions that manage drug therapy and providers being able to anticipate potential non-adherence $[9,10]$. However, overall, the evidence about whether interventions that target medication non-adherence are favorable in terms of health outcomes and cost is ambiguous [11-14]. Many interventions had unfavorable cost-effectiveness ratios [15] or were dominated. Best-practice interventions have yet to be identified [16].

Outside evaluation of programs to manage adherence, associations between medication adherence, health outcomes and cost of health care have been shown [17-22]. Higher adherence levels are associated with reduced hospital admissions $[23,24]$ and reduced mortality $[25,26]$ from selected chronic diseases such as diabetes and hypertension. Although higher adherence levels may cause increases in initial pharmaceutical costs, overall health care costs may decline due to the health services cost offset [27]. Reasons for medication nonadherence have been found to fall into several categories: the health system, the condition, patient characteristics, the therapy, and socioeconomic factors [28].

One potential determinant of adherence is the extent of innovation embodied in, or 'quality' of, the drug agent; this is the subject of this study. ${ }^{1}$ This factor that captures productivity aspects of drug treatment has not been considered in the vast literature on the determinants of medication adherence. Evidence exists that pharmaceutical innovation has contributed at significant levels to increase longevity [29]. Also, diseases subject to more rapid pharmaceutical innovation have experienced larger declines in work- and school-loss days [30]. The theoretical and empirical economic literature on the role of technological change in economic growth and the marketing literature on the role of product quality and

\footnotetext{
${ }^{1}$ We consider quality in terms of the effectiveness of a drug which comprises all features (including clinical effectiveness and side-effect profiles) to affect a treatment episode. It is not restricted to the quality of the pharmaceutical product that stems from the manufacturing process.
}

repurchasing behavior provide the conceptual framework to analyze the relationship between the vintage of a drug and average drug quality to capture productivity and the subsequent relationship between drug quality and repurchase behavior, reflected by medication adherence.

The objective of this study is to investigate whether patients who use newer (i.e. later vintage) drugs are more adherent to pharmacotherapy than patients using older drugs within the same therapeutic class, ceteris paribus. We will control for potentially confounding factors of productivity of drug treatment, most importantly unobserved patient heterogeneity and promotional activities.

\section{The impact of drug vintage on medication adherence}

Our basic hypothesis is that adherence is positively related to the quality of drugs used to treat a condition. Quality is undoubtedly multidimensional, and we do not believe that there is a single, widely-accepted measure of drug quality. However, many economists have argued that, in the case of research-intensive goods like pharmaceuticals, newer (latervintage) goods tend to be of higher quality than older goods [31-34]. Solow was the first to hypothesize that most technological change is embodied in new goods [34]. To benefit from technological change, one must use later-vintage goods or services. Therefore, product vintage has become a widelyaccepted determinant of average product quality: [32, 34-36]. ${ }^{2}$ For example, as noted by Jovanovic and Yatsenko [35], in "the Spence-Dixit-Stiglitz tradition [...] new goods [are] of higher quality than old goods." Grossman and Helpman [32] developed "a model of repeated product improvements in a continuum of sectors; each product follows a stochastic progression up a quality ladder." Solow [34] argued that "improvements in technology affect output only to the extent that they are carried into practice $[. .$.$] by the re-$ placement of old-fashioned equipment by the latest models [...]". Aghion and Howitt [33] state that "[t]echnological progress, the mainspring of long-run economic growth, comes from innovations that generate new products, processes and markets." These "[i]nnovations in turn are the result of deliberate research and development activities that arise in the course of market competition. These Schumpeterian observations constitute the starting point of that branch of endogenous growth theory built on the metaphor of quality improvements..." Using these insights allows developing "a growth model with quality-improving innovations" to analyze microeconomic issues such as performed in this study.

Translating the vintage concept to pharmaceuticals, newer agents may be more clinically effective on average compared

\footnotetext{
${ }^{2}$ One definition of vintage is "a period of origin or manufacture." [37]
} 
to older agents. In addition, newer agents may have characteristics that improve the ease of drug administration and have better side-effect profiles, all of which could improve adherence levels of patients. Less frequent dosing, one feature of drug quality, has been shown to improve adherence [38]. When patients do not need to take their medicines as often, the ease of medication use is improved. However, characteristics of a drug other than dose frequency may influence the propensity of patients who use the drug to be adherent. Of note is that key decision-makers of drug therapy (patients and providers alike) may not be aware of a drug's vintage such that the decision to use a drug is typically not made based on a drug's newness. However, drug vintage is an important proxy for a drug's average quality in terms of effectiveness and ease of use which has an impact on adherence.

Regarding the quality ladders in biomedical innovation, some authors have argued that most new drugs have not provided real advances over existing drugs. This means that the average quality of newer drugs is not necessarily higher the average quality of older drugs. On the basis of limited evidence, a systematic review of new drugs for over 100 indications approved by the US Food and Drug Administration found that superior efficacy on clinical outcomes was confirmed in less than $10 \%$ of cases [39]. Wieseler et al. state that the proportion of true innovation is less than $15 \%$ [40]. For cancer drugs, evidence suggests that most drugs approved by the European Medicines Agency had been approved with no evidence of clinically meaningful benefit for patient relevant outcomes in the period 2009-2013 [41]. This notion would suggest that there should be little or no correlation between a drug's vintage and changes in health. However, there are a number of studies that have demonstrated a substantial impact of pharmaceutical innovation, measured by changes or differences in drug vintage, on health outcomes [1, 29, 30]. For example in US cancer patient, Lichtenberg has shown that there are highly significant correlations across cancer sites between the number of new drugs launched and changes in outcomes [42, 43]. Across countries, evidence further suggests an inverse relationship between the relative number of drugs available and mortality- or disability-related outcomes $[44,45]$. When considering other factors that are likely to be confounders of the relationship between vintage and health outcomes (for example income and education), one study found that controlling for ten other potential determinants of longevity increased the estimated effect of pharmaceutical innovation by about $32 \%$ [46]. Given this literature, we assume a similar relationship to exist for adherence and drug vintage.

In parallel, marketing scholars consider consumer behavior models in which consumer perceptions and evaluations of product features influence repurchasing behavior [47, 48]. The attitudes towards perceived quality in product evaluations relative to other brands have been identified as strong predictors of brand satisfaction and loyalty which lead to product repurchase [49]. In the context of R\&D-intensive markets, perceptions of brand innovativeness influence perceived product quality [47]. We argue that individuals who use higher quality goods are more likely to repurchase these goods compared to lower quality goods and that adherence reflects repurchase behavior. While the marketing literature has focused on identifying perceptions of product quality based on attitudinal evaluations of consumers, the economics literature has established the vintage concept that defines the relationship between product features and the overall product performance relative to other goods of the same type. Thus, the hypotheses that vintage is an indicator of product quality which implies that the average quality of newer (later-vintage) drugs is higher than the average quality of older (earliervintage) drugs, and that quality has a positive effect on adherence, imply that patients should be more adherent to newer drugs.

In considering the quality of the drug, we need to account for unobserved patient heterogeneity to perform a valid analysis of the effect of pharmaceutical innovation on adherence. Adherence behavior is influenced by socio-economic and demographic factors at the individual level $[50,51]$. The healthy-adherer bias recognizes a tendency of individuals who otherwise engage in healthy behaviors to also be adherent to medication therapy. Such behaviors may be associated with higher socio-economic status [52]. In line with this, the marketing literature suggests that individual perceptions of product quality have been shown to differ systematically across consumer groups [53]. The setting in which a product is used is especially important if (1) the goods are experience goods and, (2) the consumer is, at least to some extent, a co-creator of the value gained in using a particular product (e.g. drug). Then, heterogeneity of the perceptions of product quality goes beyond demographic information $[53,54]$.

\section{Methods}

\subsection{Data}

We use the Truven Health Marketscan commercial claims and encounters database, which provides complete pharmacy and medical claims data for about 50 million insured employees and dependents between 2008 and 2013. For analysis, we use the $1 \%$ random sample draw of enrollees provided by the National Bureau of Economic Research. To identify patients that initiate drug therapy and for whom adherence behavior could be measured for a period of 365 days, we included all individuals that were enrolled for more than three consecutive years.

Data on promotional activities (i.e. sampling) were obtained from the Medical Expenditures Panel Survey (MEPS), 
which includes data on prescription drug use by the US noninstitutionalized population [55]. We measure marketing activities by the population-weighted number of free samples provided to patients at drug level on an annual basis [56]. At drug level, we then matched data on sampling at national level with our individual-level data to measure the extent of sampling of drugs that individual $i$ uses, such that the level of sampling at drug class level varies across individuals by the specific drugs prescribed.

Drugs for chronic conditions were identified by National Drug Codes and the Truven Redbook [57]. We use the classification of a therapeutic class provided in the Redbook for the definition of drug classes. To measure drug vintage, we combined the prescription claims data with the National Drug Code Directory and the Drugs@FDA database [58].

\subsection{Cross sectional comparisons of adherence levels and drug vintage}

We use cross-sectional comparisons to estimate the impact of drug vintage on adherence. Our unit of observation is drug class by patient. In observing patient-drug class combinations, we account for the fact that individuals with chronic conditions typically receive prescriptions from multiple drug classes that have different mechanisms and side effect profiles. We will account for unobserved heterogeneity of patients by using person-level fixed effects. For patient $i$ receiving prescriptions in drug class $c$, we postulate the following general linear model:

$$
\begin{aligned}
\text { adherence }_{i c}= & \beta_{1} \cdot R X_{-} \text {vintage }_{i c}+\beta_{2} \cdot \text { samples }_{i c}+\Pi \cdot X_{i c} \\
& +\alpha_{\mathrm{c}}+\gamma_{i}+\varepsilon_{i c},
\end{aligned}
$$

adherence $_{i c}$ is the extent of individual $i$ 's adherence to drugs in therapeutic class $c$, i.e. his or her medication possession ratio (MPR) during the first year of drug therapy. $R X$ vintage ${ }_{i c}$ denotes the mean vintage of drugs in therapeutic class $c$ used by patient $i$, weighted by the number of days supplied of each drug in that class. samples $_{i c}$ denotes the share of days supplied for which manufacturers have dispensed samples and which are used by individual $i .^{3} \boldsymbol{\Pi} \boldsymbol{X}_{\boldsymbol{i c}}$ is the vector of the covariates that influence adherence at drug class level. $\gamma_{i}$ is a fixed effect for individual $i . \alpha_{\mathrm{c}}$ is a fixed effect for therapeutic class $c . \varepsilon_{i c}$ is the disturbance term.

We operationalize drug vintage $\left(R X\right.$ vintage $\left._{i c}\right)$ by two variables, i.e., the Food and Drug Administration (FDA) approval year and the FDA therapeutic potential status. We hypothesize that adherence to newer (later-vintage) drugs is greater than

\footnotetext{
${ }^{3}$ samples $_{i c}=\left(\sum_{d} D A Y S U P P_{i d c} \cdot\right.$ samples $\left._{d}\right) /\left(\sum_{d} D A Y S U P P_{i d c}\right)$, where $D A Y S U P P_{i d c}$ is the number of days of drug $d$ in therapeutic class $c$ supplied to individual $i$, and samples $_{d}$ is number of samples reported in the Medical Expenditures Panel Survey in the year the patient used drug $d$.
}

adherence to older drugs. We use the year a drug was first approved by the FDA as our primary measure of drug vintage. This measure has been used previously to analyze the impact of pharmaceutical innovation on life expectancy and disability days [30]. Accordingly, the variable $F D A_{-} Y E A R_{i c}$ denotes the weighted mean FDA approval year of the drugs in class $c$ consumed by patient $i$, weighted by the number of days supplied to individual $i$ of each drug in that therapeutic class. ${ }^{4}$ If a patient received multiple active ingredients in the same drug class, we weight the FDA approval year by the number of days supplied of drugs approved in that year. We further classify the year of FDA approval into four periods: before 1980, between 1981 and 1990, between 1991 and 2000, and after 2000.

FDA drug approval requires that a drug be safe and effective, but not that it be superior in comparison with other drugs [59]. When the FDA begins to review a new drug for approval, it assesses the drug's "therapeutic potential," i.e. whether it is an advance over available therapies [60]. Accordingly, the FDA designates the drug as either a priority-review drug or as a standard-review drug. Besides year of drug approval, we consider this classification as an indicator of a drug's effective vintage compared to its actual vintage [30]: the effective vintage of a standard-review drug may be earlier than its actual vintage. ${ }^{5}$ We define the variable priority $\%_{i c}$ as the share of days supplied to individual $i$ of drugs in $\operatorname{drug}$ class $c$ that have been awarded priority review status. ${ }^{6}$

We control for situational factors of adherence behavior expressed by the term $\boldsymbol{X}_{\boldsymbol{i c}}$ of eq. (1) which includes both the pecuniary and non-pecuniary costs of adhering to drug therapy. We measure promotional activities by the number of free samples provided at the national level in a drug class, defined by the variable samples. Controlling for promotional activity could cause the effect of vintage on adherence to be underestimated, since it has been shown that newer drugs are more frequently advertised [61]. As promotional activity typically increases utilization of competing drugs and that of the promoted brand [62], we do not account for variations in promotional activity at brand level. Direct pecuniary cost is typically expressed by the level of copayments for which we calculate the patient copayment per day of therapy (variable copay_day). Other non-pecuniary cost refers to factors other than out-of-pocket payments that may enhance or hinder medication adherence. We included the share of prescriptions filled via mail-order pharmacy (variable mail\%). Finally, we

\footnotetext{
$\overline{{ }^{4} F D A_{-} Y E A R_{i c}}=\left(\sum_{d} D A Y S U P P_{i d c} \cdot F D A_{-} Y E A R_{d}\right) /\left(\sum_{d} D A Y S U P P_{i d c}\right)$, where $D A Y S U P P_{i d c}$ is the number of days of drug $d$ in therapeutic class $c$ supplied to individual $i$, and FDA_YEAR is is FDA approval year of drug $d$.

${ }^{5}$ For example, if a standard review drug approved in 2013 is considered equivalent to a drug approved in 2003 , its effective vintage is 2003 whereas its actual vintage is 2013 .

${ }^{6}$ PRIORITY\% $_{i c}=\left(\sum_{d} D_{D A Y S U P P}{ }_{i d c} \cdot\right.$ PRIORITY $\left._{d}\right) /\left(\sum_{d} D A Y S U P P_{i d c}\right)$, where PRIORITY $_{d}=1$ if any product containing drug $d$ was priority review and 0 otherwise.
} 


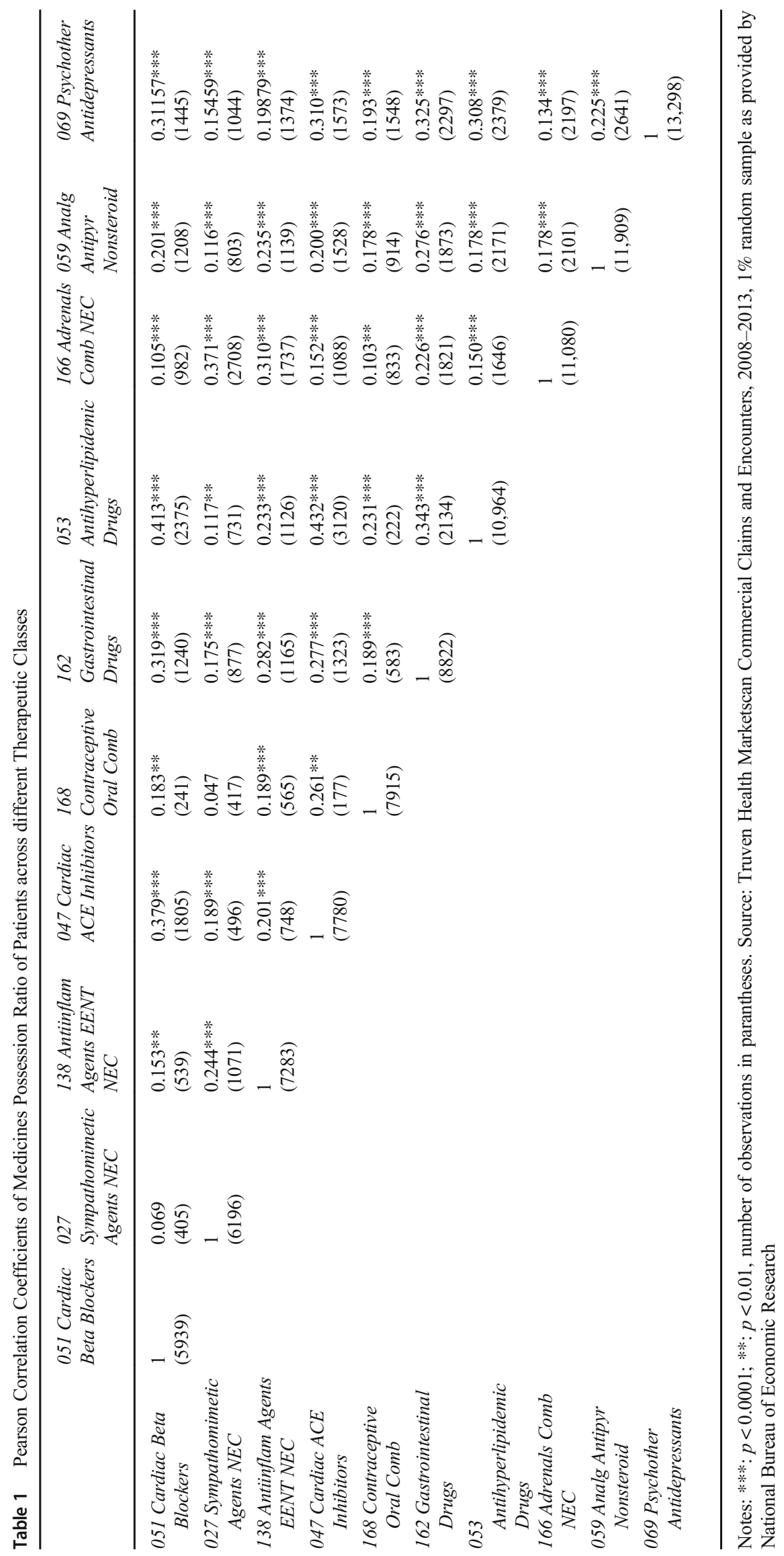


Table 2 Mean medicines possession ratio and FDA approval year of top 30 therapeutic drug classes

\begin{tabular}{|c|c|c|c|}
\hline Therapeutic drug class & $N$ (patients) & MPR: mean (std) & $\begin{array}{l}\text { FDA approval year: } \\
\text { mean (std) }\end{array}$ \\
\hline 069-Psychother Antidepressants & 17,683 & $58.49 \%(31.36 \%)$ & $1990.64(10.39)$ \\
\hline 059-Analg/Antipyr Nonsteroid/Antiinflam & 15,794 & $21.11 \%(22.85 \%)$ & $1983.02(10.22)$ \\
\hline 053-Antihyperlipidemic Drugs NEC & 14,841 & $67.12 \%(30.07 \%)$ & $1993.21(7.01)$ \\
\hline 166-Adrenals \& Comb NEC & 14,471 & $16.92 \%(22.32 \%)$ & $1968.29(16.18)$ \\
\hline 162-Gastrointestinal Drugs Misc NEC & 12,020 & $51.95 \%(32.23 \%)$ & $1994.03(5.84)$ \\
\hline 168-Contraceptive Oral Comb NEC & 10,929 & $67.88 \%(30.97 \%)$ & $1958.05(5.59)$ \\
\hline 047-Cardiac ACE Inhibitors & 10,702 & $69.44 \%(30.37 \%)$ & $1986.04(2.93)$ \\
\hline 138-Antiinflam Agents EENT NEC & 9429 & $29.83 \%(20.32 \%)$ & $1992.80(4.54)$ \\
\hline 051-Cardiac Beta Blockers & 8293 & $68.36 \%(30.99 \%)$ & $1985.14(10.35)$ \\
\hline 027-Sympathomimetic Agents NEC & 8133 & $19.01 \%(16.63 \%)$ & $1983.34(4.57)$ \\
\hline 178-Thy/Antithy Thyroid Hormones & 6579 & $78.60 \%(26.73 \%)$ & $1999.55(3.91)$ \\
\hline 052-Cardiac Calcium Channel & 6037 & $71.15 \%(30.17 \%)$ & $1989.76(4.74)$ \\
\hline 174-Antidiabetic Agents Misc & 5496 & $64.46 \%(29.56 \%)$ & $1996.22(2.78)$ \\
\hline 046-Cardiac Drugs. NEC & 5467 & $73.42 \%(28.65 \%)$ & $1990.78(8.38)$ \\
\hline 068-Anticonvulsants Misc & 5443 & $53.69 \%(32.01 \%)$ & $1992.72(6.23)$ \\
\hline 170-Estrogens \& Comb NEC & 4693 & $60.43 \%(32.18 \%)$ & $1972.23(13.94)$ \\
\hline 071-Stimulant Amphetamine Type & 4651 & $57.29 \%(29.00 \%)$ & $1973.63(21.11)$ \\
\hline 248-Leukotriene Modifiers & 4515 & $53.25 \%(30.72 \%)$ & $1997.99(0.16)$ \\
\hline 224-Vitamin D NEC & 4490 & $37.21 \%(24.96 \%)$ & $1942.43(7.41)$ \\
\hline 124-Diuretics Thiazides \& related & 4435 & $66.21 \%(31.34 \%)$ & $1959.60(3.24)$ \\
\hline 195-Antiinflam S/MM Agnts \& Comb Misc & 3415 & $12.50 \%(10.25 \%)$ & $1963.85(12.05)$ \\
\hline 234-Unclassified Agents NEC & 3303 & $58.29 \%(32.92 \%)$ & $1996.60(5.79)$ \\
\hline 001-Antihistamines \& Comb NEC & 3044 & $42.70 \%(29.41 \%)$ & $2002.64(7.67)$ \\
\hline 177-Progestins NEC & 2606 & $47.57 \%(33.57 \%)$ & $1962.49(4.97)$ \\
\hline 123-Diuretics Potassium-Sparing & 2591 & $64.39 \%(30.79 \%)$ & $1964.61(4.38)$ \\
\hline 011-Antibiot Tetracyclines & 2550 & $36.08 \%(23.85 \%)$ & $1968.61(5.38)$ \\
\hline 250-Phosphodiesterase Inhibitors & 2416 & $25.46 \%(23.80 \%)$ & $2000.58(2.45)$ \\
\hline 232-Multivit Prep Multivit Prenatal & 2377 & $52.82 \%(26.91 \%)$ & $1967.65(4.02)$ \\
\hline 060-Anal/Antipyr Opiate Agonists & 2288 & $28.06 \%(33.40 \%)$ & $1966.08(18.82)$ \\
\hline
\end{tabular}

Source: Truven Health Marketscan Commercial Claims and Encounters, 2008-2013, 1\% random sample as provided by National Bureau of Economic Research control for the year in which an individual started drug therapy.

\subsection{Accounting for unobserved heterogeneity of patients}

It has been shown that there are likely to be both observed (e.g. socio-economic status) and unobserved (e.g. "healthyadherer") individual characteristics that influence adherence behavior [52, 63]. The healthy-adherer effect has been documented widely in the literature [52, 64-66]. It arises when patients who adhere to one type of therapy or prevention are more likely to engage in other healthy behaviors than their non-adherent counterparts, independent of which type of technology they use. In line with this, the literature on the effect of adherence on health outcomes has documented that not accounting for unobserved heterogeneity of healthy adherer behaviors can result in biased estimates of the effect of adherence on clinical outcomes when adherence is considered as exogenous variable [52, 64, 67]. Steiner [66] argues that single sociodemographic and clinical characteristics to guide adherence cannot predict adherence because each individual carries out a set of behaviors that interact with each other and are influenced by social and environmental considerations as well as clinical care. Belotti et al. document that the returns to adherence on health are highly heterogeneous by treatment regime and physicians [63]. Moreover, heterogeneity of patients and physicians is an important determinant of health and moderates the effect of adherence on health. Besides, estimates of adherence on health are upward biased and, the 
Table 3 Descriptive Statistics, start of therapy defined by first time therapeutic class has been prescribed

\begin{tabular}{|c|c|c|}
\hline Characteristic (variable name) & Unit & Full sample \\
\hline Sample size (patient - drug class combinations) & $n$ & 247,146 \\
\hline Sample size (patients) & $n$ & 70,896 \\
\hline Adherence (MPR) & $\begin{array}{l}\text { mean } \\
\quad(S T D)\end{array}$ & $\begin{array}{l}49.99 \% \\
\quad(34.13 \%)\end{array}$ \\
\hline FDA approval year (FDA_year) & $\begin{array}{l}\text { mean } \\
\quad(S T D)\end{array}$ & $\begin{array}{r}1982.32 \\
(16.48)\end{array}$ \\
\hline \multicolumn{3}{|l|}{$\%$ days supplied with FDA approval year } \\
\hline before 1980 & $\%$ & $31.06 \%$ \\
\hline between 1981 and 1990 & $\%$ & $20.74 \%$ \\
\hline between 1991 and 2000 & $\%$ & $39.14 \%$ \\
\hline after 2000 & $\%$ & $9.06 \%$ \\
\hline FDA priority status (priority\%) & $\%$ & $42.84 \%$ \\
\hline $\begin{array}{l}\text { Promotional activity (number of free samples } \\
\text { received by patients in drug class for each } \\
100 \text { days supplied per 1,000,000 US } \\
\text { non-institutionalized population) }\end{array}$ & $\begin{array}{l}\text { mean } \\
\text { (STD) }\end{array}$ & $\begin{array}{l}1.11 \\
\quad(3.26)\end{array}$ \\
\hline Mail-order prescriptions (mail\%) & $\%$ & $17.87 \%$ \\
\hline Copayment / day (copay_day) & $\begin{array}{l}\text { mean } \\
\quad(S T D)\end{array}$ & $\begin{array}{l}0.47 \\
\quad(0.97)\end{array}$ \\
\hline Patient age (age) & $\begin{array}{l}\text { mean } \\
\quad(S T D)\end{array}$ & $\begin{array}{l}42.60 \\
\quad(0.49)\end{array}$ \\
\hline Patient gender (\% male) & $\%$ & $40.11 \%$ \\
\hline
\end{tabular}

FDA: Food and Drug Administration; Sources: Truven Health Marketscan Commercial Claims and Encounters, 2008-2013, 1\% random sample as provided by National Bureau of Economic Research; Drugs@FDA Data Files (https://www.fda.gov/drugs/drug-approvals-and-databases/drugsfda-data-files) moderation effect of patient heterogeneity on adherence is larger than physician heterogeneity. Accordingly, we assume that accounting for unobserved patient heterogeneity is equally important when adherence is considered as endogenous variable.

In this study, we observe adherence to different types of drugs used by the same individual but not other health-related behaviors such as prevention. We include patient level fixed effects, denoted by $\gamma_{i}$ for individual $i$ to account for characteristics (e.g. age, education, marital status, number of comorbidities) that are invariant across a patient's medical condition and may be correlated with drug vintage, including healthyadherer behaviors. Moreover, we assume that physicianpatient interactions are captured in the patient fixed effects, especially preferences of the providers visited and health plan characteristics at individual level. Choices made by prescribers and pharmacies for the underlying drug formularies such as prior authorization or other choices and the interactions with patient behavior likely influence patient behavior [68]. Of note is that patient level fixed effects do not capture whether the same individual behaves differentially across different technologies (i.e. drugs) used that relate to the within individual level heterogeneity of environment, socio-economic factors, tastes and preferences besides the quality of the drug.
Descriptive analysis of our sample data shows that the number of patients using multiple drug classes is substantial. $87 \%$ of patients are prescribed at least two drug classes or more in the first year of treatment when conditioning on a patient having a diagnosis for a chronic disease as described below. For example, our sample includes data on 10,741 hypertension patients. The mean number of drug classes per patient is 5.63 , so the number of observations is $10,741 * 5.63=60,525$ observations. To analyze the extent to which, conditional on being a below(above-) average adherer to one class of drugs, the individual is also a below- (above-) average adherer to other classes, we calculated bivariate correlations between adherence levels of the same individual to all drug classes considered in the empirical analysis at the drug class level. Using an unbalanced correlation matrix, we find that across 128 drug classes, the median correlation is 0.13 . Calculating Pearson correlations of the Medicines Possession Ratio within patients, we reject the null hypothesis that these correlations are equal to zero. Table 1 shows a matrix of the unbalanced cross correlations of the 10 drugs classes most frequently used by patients that are conditional on the patients receiving prescriptions in both drug classes. 
Table 4 Estimates of medicines possession ratio by product vintage - pooled regressions

\begin{tabular}{|c|c|c|c|c|c|}
\hline & & $\begin{array}{l}\text { Model } 1 \\
\text { (drug vintage } \\
\text { continous) }\end{array}$ & $\begin{array}{l}\text { Model } 2 \\
\text { (drug vintage } \\
\text { by decades) }\end{array}$ & $\begin{array}{l}\text { Model } 1 a \\
\text { (no person } \\
\text { level FE) }\end{array}$ & $\begin{array}{l}\text { Model } 1 \mathrm{~b} \\
\text { (excluding } \\
\text { situational factors) }\end{array}$ \\
\hline \multicolumn{6}{|l|}{ Drug quality } \\
\hline FDA approval year (FDA_year) & & $\begin{array}{r}0.0025 * * * \\
(0.0001)\end{array}$ & & $\begin{array}{r}0.0030 * * * \\
(0.0001)\end{array}$ & $\begin{array}{r}0.0026^{* * * *} \\
(0.0001)\end{array}$ \\
\hline FDA approval year (categorical) & $\begin{array}{l}\text { later than } 2000 \\
\text { between } 1991 \\
\text { and } 2000 \\
\text { between } 1981 \\
\text { and } 1990 \\
\text { before } 1980\end{array}$ & & $\begin{array}{r}0.0804 * * * \\
(0.0035) \\
0.0821 * * * \\
(0.0026) \\
0.0424 * * * \\
(0.0025)\end{array}$ & & \\
\hline FDA priority status (priority\%) & & $\begin{array}{r}0.0087 * * * \\
(0.0019)\end{array}$ & $\begin{array}{r}0.0128 * * * \\
(0.0020)\end{array}$ & $\begin{array}{r}0.0090 * * * \\
(0.0018)\end{array}$ & $\begin{array}{r}0.0112 * * * \\
(0.0020)\end{array}$ \\
\hline \multicolumn{6}{|l|}{ Situational factors } \\
\hline Promotional activity (samples) & & $\begin{array}{r}0.0019 * * * \\
(0.0000)\end{array}$ & $\begin{array}{r}0.0021 * * * \\
(0.0000)\end{array}$ & $\begin{array}{r}0.0023 * * * \\
(0.0000)\end{array}$ & \\
\hline $\begin{array}{l}\text { Share of days supplied via mail-order } \\
\text { pharmacy (mail\%) }\end{array}$ & & $\begin{array}{r}0.3289 * * * \\
(0.0035)\end{array}$ & $\begin{array}{r}0.3302 * * * * \\
(0.0035)\end{array}$ & $\begin{array}{r}0.1876 * * * \\
(0.0016)\end{array}$ & \\
\hline Prices: copayment / day (copay_day) & & $\begin{array}{c}-0.0362 * * * \\
(0.0009)\end{array}$ & $\begin{array}{c}-0.0351 * * * \\
(0.0009)\end{array}$ & $\begin{array}{r}-0.0376^{* * * *} \\
(0.0008)\end{array}$ & \\
\hline Fixed effect individual & & yes & yes & no & yes \\
\hline Fixed effect therapeutic class & & yes & yes & yes & yes \\
\hline Fixed effect year started therapy & & yes & yes & yes & yes \\
\hline$R$-Squared & & 0.717 & 0.717 & 0.391 & 0.695 \\
\hline Root MSE & & 0.218 & 0.218 & 0.267 & 0.226 \\
\hline $\mathrm{N}$ & & 248,597 & 248,597 & 248,597 & 248,597 \\
\hline
\end{tabular}

Note: ***:p $<0.0001 ; * *: p<0.01 ; *<0.05 ;$ FDA: Food and Drug Administration; Standard errors are in parantheses. Sources: Truven Health Marketscan Commercial Claims and Encounters, 2008-2013, 1\% random sample as provided by National Bureau of Economic Research; Drugs@FDA Data Files (http://www.fda.gov/drugs/drug-approvals-and-databases/drugsfda-data-files)

To assess the appropriateness of person-level fixed effects empirically, we also estimate a set of regression models including the patient's age, gender and information about comorbidity structure instead (Supplementary Material). Chi-squared statistics suggested the superiority of the fixed effects approach. ${ }^{7}$ In the models that include individual level fixed effects, F-statistics suggest that individual level fixed effects explain a significant portion of the variance.

\subsection{Measures of medication adherence}

We measure adherence levels by the medication possession ratio (MPR) in the 365 days after the first prescription for patient $i$ in drug class $c$. The MPR is the days supplied of the drug class dispensed during the follow-up year divided by the number of days in that same year. We truncated MPRs higher than $100 \%$ because we cannot

\footnotetext{
${ }^{7}$ Using the absorb statement of the GLM procedure in SAS, we also include patients using one drug class only. Results were similar with regard to effect sizes and significance levels when we excluded these patients.
}

distinguish inappropriate behaviors such as overuse and early refills from appropriate behaviors such as changes in drug regimens or combination therapies [4]. Within the same drug class, physicians may switch therapy within the class for different reasons. This is the case in about $15 \%$ of patient/drug-class observations of our sample. In that case, we calculated weighted averages for our outcome measures and the by the number of days supplied by the physician. ${ }^{8}$ Also, we calculated the weighted average of FDA approval year by the number of days supplied and adherence levels in the same period of time. Thus, for our variable of interest, we measure whether on average the

\footnotetext{
${ }^{8}$ For example, a patient starts simvastatin, which obtained FDA approval in 1991, and her LDL (bad cholesterol) does not decline sufficiently after six months. For example, this therapy lasts 245 days for which the patient is not fully adherent because the number of days supplied was 200 , i.e. $M P R_{1}=\frac{200}{245}=81.63 \%$. The physician then switches to a newer statin that the patient remains on for the remainder of the year which also increased HDL (good cholesterol) levels, for example pitavastatin that was approved in 2009. Again, we capture the number of days supplied, e.g. 120 days or $M P R_{2}=\frac{120}{120}=100 \%$ such that the weighted MPR in the statin class is $M P R_{1} * \frac{245}{365}+M P R_{2} * \frac{120}{365}=87.67 \%$.
} 
Table 5 Estimates of medicines possession ratio by product vintage - regressions by five major health conditions

\begin{tabular}{|c|c|c|c|c|c|}
\hline & $\begin{array}{l}\text { Hypertension } \\
\text { (Model 3) }\end{array}$ & $\begin{array}{l}\text { Hyper- } \\
\text { cholesterolemia } \\
\text { (Model 4) }\end{array}$ & $\begin{array}{l}\text { Diabetes } \\
\text { (Model 5) }\end{array}$ & $\begin{array}{l}\text { Hypothyroidism } \\
\text { (Model 6) }\end{array}$ & $\begin{array}{l}\text { Osteoporosis } \\
\text { (Model 7) }\end{array}$ \\
\hline \multicolumn{6}{|l|}{ Drug quality } \\
\hline FDA approval year (FDA_year) & $\begin{array}{r}0.0029 * * * \\
(0.0003)\end{array}$ & $\begin{array}{r}0.0031 * * * \\
(0.0003)\end{array}$ & $\begin{array}{r}0.0023 * * * \\
(0.0005)\end{array}$ & $\begin{array}{r}0.0036 * * * \\
(0.0005)\end{array}$ & $\begin{array}{r}0.0036 * * * \\
(0.0006)\end{array}$ \\
\hline FDA priority status (priority\%) & $\begin{array}{r}0.0262 * * * \\
(0.0060)\end{array}$ & $\begin{array}{l}0.0080 \\
\quad(0.0064)\end{array}$ & $\begin{array}{l}0.0183 \\
\quad(0.0096)\end{array}$ & $\begin{array}{l}0.0323 * \\
\quad(0.0128)\end{array}$ & $\begin{array}{l}0.0321^{*} \\
\quad(0.0149)\end{array}$ \\
\hline \multicolumn{6}{|l|}{ Situational factors } \\
\hline Promotional activity (samples) & $\begin{array}{l}0.0033^{* *} \\
(0.0010)\end{array}$ & $\begin{array}{l}0.0037 * * \\
(0.0010)\end{array}$ & $\begin{array}{l}0.0028 \\
\quad(0.0020)\end{array}$ & $\begin{array}{l}0.0065^{* *} \\
\quad(0.0020)\end{array}$ & $\begin{array}{l}0.0030 \\
\quad(0.0020)\end{array}$ \\
\hline Share mail-order prescriptions (mail\%) & $\begin{array}{r}0.3579 * * * \\
(0.0134)\end{array}$ & $\begin{array}{r}0.3282 * * * \\
(0.0137)\end{array}$ & $\begin{array}{r}0.3367 * * * \\
(0.0220)\end{array}$ & $\begin{array}{r}0.3373 * * * \\
(0.0297)\end{array}$ & $\begin{array}{r}0.3850 * * * \\
(0.0327)\end{array}$ \\
\hline $\begin{array}{l}\text { Prices: copayment / day } \\
\text { (copay_day) }\end{array}$ & $\begin{array}{c}-0.0294 * * * \\
(0.0042)\end{array}$ & $\begin{array}{c}-0.0350 * * * \\
\quad(0.0046)\end{array}$ & $\begin{array}{r}-0.0644 * * * \\
(0.0085)\end{array}$ & $-0.0091(0.0064)$ & $\begin{array}{l}-0.0284^{*} \\
\quad(0.0125)\end{array}$ \\
\hline Person-level Fixed Effects & yes & yes & yes & yes & yes \\
\hline Therapeutic Class Fixed Effects & yes & yes & yes & yes & yes \\
\hline Year started therapy & yes & yes & yes & yes & yes \\
\hline $\begin{array}{l}\text { Patient }- \text { drug class } \\
\text { combinations }(N)\end{array}$ & 60,525 & 49,431 & 23,249 & 16,778 & 9757 \\
\hline Patients (N) & 10,741 & 10,061 & 3455 & 3232 & 1981 \\
\hline Therapeutic Classes (N) & 13 & 13 & 16 & 12 & 12 \\
\hline RSquare & 0.760 & 0.803 & 0.774 & 0.795 & 0.795 \\
\hline RootMSE & 0.195 & 0.182 & 0.186 & 0.187 & 0.197 \\
\hline
\end{tabular}

Note: ***:p <0.0001; **:p<0.01;*<0.05; FDA: Food and Drug Administration; Standard errors are in parantheses. Sources: Truven Health Marketscan Commercial Claims and Encounters, 2008-2013, 1\% random sample as provided by National Bureau of Economic Research; Drugs@FDA Data Files (https://www.fda.gov/drugs/drug-approvals-and-databases/drugsfda-data-files)

mean vintage of drugs in a particular drug class is related to improved adherence behavior, i.e. as in the footnote $R X$ vintage $_{1} \cdot \frac{120}{365}+R X_{\text {vintage }_{2}} \cdot \frac{245}{365}=2003.08$.

\subsection{Identification of patients and health conditions}

We analyze adherence levels of patients in their first year of drug therapy since adherence levels vary by the duration of drug therapy [69]. Thus, we restrict our sample to patients who were considered healthy and initiate medical encounters for the first time to control for initial health status. We include pharmacy claims of individuals if they showed no pharmacy, inpatient or outpatient claims in a period of at least twelve months before the indexing date, the earliest possible date as of January 1st 2008. We use this approach also to reduce potential reverse causality issues.

We use two different strategies to identify start of drug therapy. First, we identify the initiation of drug therapy by the earliest date a patient received prescriptions in drug class $c$ (models 1-2). As a second method, we identify patients by their earliest date of diagnosis recorded in the claims data in a set of five chronic conditions (models 3-7). Based on ICD-9CM classifications, we include hypercholesterolemia, hypertension, diabetes, hypothyroidism and, osteoporosis, as they are common in the US employed population [4]. Patients needed to have at least two claims for the same diagnosis to reduce the risk that diagnoses were not stated randomly. In the disease-specific regressions (models 3-7), the aim was to obtain condition-specific estimates of the effect of drug vintage on adherence. Here, we exclude drug classes with a prescription volume of less than $2 \%$ per condition. The Chow test indicates that it is appropriate to estimate five separate regression models by chronic condition [70]. All statistical analyzes were performed using SAS version 9.4.

\section{Results}

\subsection{Descriptive analysis}

Table 2 shows descriptive statistics of our data. ${ }^{9}$ The mean FDA approval year of the drugs studied in the full sample is 1982 with a standard deviation of 16 years, indicating large variation in the vintages of drugs used. Most prescriptions filled during the period 2009-2013 (39\%) are for drugs

\footnotetext{
${ }^{9}$ Descriptive statistics for patients identified by health condition are documented in the Appendix Tables.
} 
Fig. 1 Predicted effect of drug vintage on medicines possession ratio (MPR) by FDA approval year in patients in their first year of therapy, US employed population, controlling for situational factors (promotional activity, copayments and distribution channel), including individual level and drug class-level fixed effects

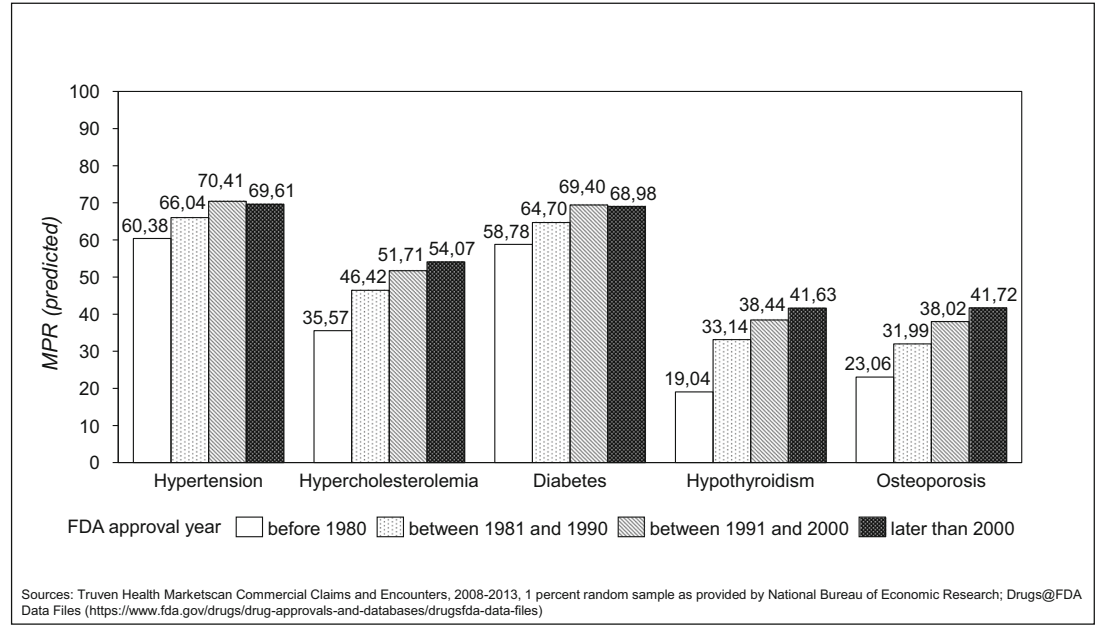

approved between 1991 and 2000. Across the full sample, $43 \%$ of days supplied are for drugs that had FDA priorityreview status. $18 \%$ of days supplied are filled via mail-order pharmacies. The average copayment per day is $\$ 0.47$.

We identify considerable variation in vintage at drug class level by chronic condition in our study sample. Table 3 shows the mean MPR and FDA approval year for the 30 drug classes with the highest prescription volume.

\subsection{Effect of vintage on adherence in first year of drug therapy by therapeutic class}

Estimates of eq. (1) when the five chronic conditions are pooled are presented in Table 4. Our results suggest that adherence increases (i.e., the MPR is higher) if the drug used in a particular drug class is newer and if it has received priority review status. In Model 1, the MPR increases by 0.0025 if the FDA approval year increases by one year. This means that a 10-year increase in the FDA approval year raises the mean MPR by 2.5 percentage points across all therapeutic classes, on average. If the drug has received FDA priority review status, the MPR increases by 0.0087 . Moreover, we find a small positive significant effect of the number of samples provided on the MPR of 0.0019 . This means that when one additional sample was provided per 100 days supplied in 1 million population, the MPR increases by 0.19 percentage points. This further suggests a small indirect effect of innovation through promotional activities. If the share of prescriptions filled by mail-order pharmacy increases by one percentage point, the MPR increases by 3.29 percentage points $(p<0.001)$. A higher copayment per day has a negative effect on adherence levels $(-0.0362$ if copayment per day increased by one dollar, $\mathrm{p}<0.001)$.

Model 2 categorizes the FDA approval year into four periods. Compared to drugs that have been approved before 1980 , the effect of drug vintage on MPR is highest for drugs approved for the period between 1991 and 2000 (estimate:
0.0821) and lowest for the period between 1981 and 1990 (estimate: 0.0424). Apart from this, the effect sizes and significance levels of the covariates that reflect situational factors are similar in size and direction compared to Model 1.

When we completely refrain from potential unobserved heterogeneity at individual level and exclude individual fixed effects as expressed by $\gamma_{i}$, the estimate of FDA approval year increases slightly to 0.003 (Model 1a). In that case, the effect of vintage is slightly upward biased. Second, the effect of vintage on adherence increases to 0.0026 when we exclude price, promotion and distribution channel.

\subsection{Effect of vintage on adherence in first year of drug therapy in five chronic conditions}

Table 5 displays regressions (models 2-7) that stratify individuals by five chronic conditions. Again, we find significant effects of drug vintage on medication adherence in all chronic conditions analyzed, with the size of the effect of FDA approval year somewhat varying across conditions. The effect of FDA approval year on MPR is highest in hypothyroidism and osteoporosis (estimate: 0.0036 ) and lowest in diabetes (estimate: 0.0023 ). Whether a drug has received FDA priorityreview status has significant positive effects in the models of hypertension, hypothyroidism and osteoporosis. Promotional activities in terms of sampling significantly influenced adherence levels in the models of hypertension, hypercholesterolemia and osteoporosis. Effect sizes and significance levels of the other variables that influence adherence are similar compared to the results of the pooled regressions (models 1 and 2). Estimates of the effect of vintage on adherence are much smaller when we included person level fixed effects that relate to both observed and unobserved heterogeneity instead of including patient characteristics and comorbidity only that captures observed heterogeneity. For example, the estimate of FDA approval year decreased to 0.0029 compared to 0.0053 in hypertension patients. 
Figure 1 shows estimates of mean MPR by vintage category for each of the chronic conditions (models 3-7). We observe a strong increase in mean MPR when we compare drugs approved before 1981 with drugs approved after 1981 or after 1991. For drugs approved in the period after the year 2000, adherence levels are still higher compared to drugs before 1980 . However, the increase is smaller or slightly lower compared to drugs approved in the period between 1991 and 2000. For hypertension and diabetes, adherence levels decrease slightly, but the 1991-2000 vs. post-2000 differences are not statistically significant.

\subsection{Robustness}

Several robustness analyses substantiated the results (Supplementary Material). We a) accounted for the distributional nature of the outcome variable using log-odds of MPR instead of natural units, b) considered patient subgroups that may be more or less vulnerable to medication non-adherence (e.g. patients that do not switch across drugs in the same class, patients that use multiple brands, c) tested the mediating effects of copayment and promotional activity. Especially, part of the effect of co-payments seems to be attenuated by the level of vintage as newer drugs tend to have higher co-payments. When we exclude the variable that controls for the level of co-payment, the effect of adherence decreases in all model specifications suggesting trade-offs between the level of innovation and copayments. Finally, our results are robust when estimating models using aggregate longitudinal data. Across all robustness analyses, the effect of vintage on medication adherence was consistently significant, although somewhat varying in magnitude of the effect.

\section{Discussion}

This study has investigated the relationship between drug quality that we captured by a drug's vintage as measure of productivity of treatment and medication adherence in the US working population. We demonstrate that patients tend to be more adherent to newer drugs. The medicine possession ratio increases by 2.5 percentage points when the mean vintage of a drug increases by ten years. This effect may appear small, but our estimates indicate that a 10 -year increase in drug vintage has the same effect on medication adherence as a 0.35 USD reduction in copayment per day of therapy. Also, our estimates of vintage reflect averaged effects across all drugs of the same vintage, some of which may be more effective in terms of effectiveness than others $[39,40]$.

The effect of vintage on adherence is similar in magnitude to the effects of copayments and larger than that of promotional activity [71, 72]. A one standard deviation increase in FDA approval year is associated with an increase in adherence of 4.12 percentage points, while a one standard deviation reduction in copayment per day is associated with an increase in adherence of 3.51 percentage points. A one standard deviation increase in promotional activity is associated with an increase of 0.61 percentage points. While drugs certainly differ in efficacy for different types of condition, different levels of severity, co-morbidity with other conditions, physicians and pharmacy benefit managers should be aware that, on average, patients that use newer drugs are more adherent compared to using older drugs when making choices about certain drug agents or formulary design.

Our results further support the notion that promotional activity - measured by sampling activities of drug companies at national level - has a very small effect on adherence levels. This result confirms previous findings regarding changes in overall therapy initiation conditional on marketing activity [72]. However, effect sizes are small or economically not relevant in influencing adherence levels $[73,74]$ and this result is likely to be independent from the measure of promotional activity, as detailing and sampling were shown to be complementary [75]. Most studies that have analyzed influences from economic incentives on adherence have focused on variations in co-payment levels [76]. Our results suggest that part of the effect of co-payments may be attenuated by the level of innovation as newer drugs tend to have higher co-payments.

In this study, we demonstrate that biomedical innovation may not only have direct effects on health outcomes and health care consumption but also indirect effects via adherence. Existing studies show significant effects of drug vintage on mortality and expenditures [43-45, 77]. We contribute to this literature by showing that biomedical innovation influences adherence, and numerous studies have shown that adherence influences health outcomes. Adherence has been identified as one of the most important factors in explaining health outcomes $[63,78]$. We show that adherence levels are positively influenced by the level of drug quality (expressed by vintage) such that adherence is an important mechanism behind the relationships between drug vintage and mortality and expenditure. Thus, part of the effects of biomedical innovation on health outcomes can be attributed to the indirect effect of adherence on outcomes. Besides, we confirm the importance of accounting for patient heterogeneity to explain variations beyond sociodemographic and comorbidity characteristics in adherence levels when adherence is endogenous [66]. Estimates of adherence on health that do not account for the moderating effects of biomedical innovation and patient heterogeneity on adherence may thus lead to biased estimates of the influence of biomedical innovation on health. Managing improvements in adherence levels can be addressed more directly by health care providers than long-term effects, as these are often influenced by a large number of factors.

The magnitude of the effect on adherence of using later vintage drugs is similar to, or smaller than, the effect of some 
interventions. Two studies found that the percentage of individuals being adherent at a level higher than $80 \%$ increased by about 3.5 to 4.7 percentage points conditional on copayment structures of health care plans $[17,21]$. While we aimed to reduce biases on adherence levels by analyzing individuals in their first year of drug therapy and with a diagnosis of a chronic condition, we cannot observe the explicit prescription decisions of using later vintage drugs compared to earlier vintage drugs. Additionally, our estimates of the effects on adherence of variables that account for the non-pecuniary and pecuniary costs are similar to previous findings despite our focus on the privately-insured employed population [18, 19, 52].

We need to mention some limitations. Using claims data, we are unable to identify individuals who never filled a prescription ("primary non-adherence"). Second, we cannot observe whether patients actually consumed the drugs prescribed. Often, mailorder prescriptions are re-filled automatically. Another limitation is that we could not incorporate information about adverse events and side effects, another indicator of drug quality that may reduce adherence. Prescribing behavior is adjusted when new information about adverse events becomes available [79]. Fourth, we cannot account for heterogeneity that may arise in the same patient across different drug classes besides drug vintage, although the evidence on the healthy adherer bias suggests that patient level heterogeneity seems most important to account for individual preferences, comfort and experience. However, if individuals are differentially adherent to different drugs because of within-individual variation in factors such as preferences, comfort and experience, this could cause a potential source of endogeneity in our analysis. Relevant aspects are dimensions of side effects. For example, suppose that a patient is male and attempting to conceive a child with his partner. This patient may adhere perfectly well to drug classes that have no sexual side effects, but be a poor adherer to drugs that do. Previous approaches have emphasized individual level heterogeneity that relates to the healthy adherer bias. Future research may aim to explicitly capture within individual level heterogeneity across different drug classes. Finally, we cannot control for the mix of providers that the patient is using. In our sample, $15 \%$ of patients have received services from a single provider in the observation period. Provider decisions might contribute to variation in medication adherence and may differ in the vintage of drugs they prescribe [80, 81].

\section{Conclusions}

Our study analyzes the influence of drug vintage on medication adherence in the US employed population. We show that patients are more adherent to newer drugs within a therapeutic class, controlling for unobserved individual effects and situational factors. Patients are also more adherent to priority-review drugs, which are of later "effective vintage" than standard- review drugs. We identify promotional activities as an additional channel through which drug quality may influence adherence. Prescribers and pharmacy benefit managers should be aware that patients tend to be more adherent to newer drugs within a therapeutic class when making prescription choices.

Acknowledgments $\mathrm{KB}$ has received funding (employment) from the German Ministry of Education and Research (grant number BMBF 01EH1101A). The funding agreement ensured the authors' independence in designing the study, interpreting the data, writing, and publishing the report. Part of this work was completed while KB was Chazen Visiting Scholar at Columbia University.

This study was presented at the 2016 ASHECON Biannual Congress in Philadelphia, PA, USA and the 2016 Academy Health Annual Research Meeting, Boston, MA, USA, the 2016 EuHEA congress in Hamburg, Germany and the 2017 annual meeting of the German Health Economists Association (DGGÖ) in Basel, Switzerland.

K. Blankart and F. Lichtenberg declare they have no conflict of interest relevant to this study.

The MarketScan claims data are available from Truven Health Analytics which the authors accessed through a license provided by NBER. The data confidentiality standards do not allow any transfer, sell or access of the data and so are not publicly available.

Funding Information Open Access funding provided by Projekt DEAL.

Open Access This article is licensed under a Creative Commons Attribution 4.0 International License, which permits use, sharing, adaptation, distribution and reproduction in any medium or format, as long as you give appropriate credit to the original author(s) and the source, provide a link to the Creative Commons licence, and indicate if changes were made. The images or other third party material in this article are included in the article's Creative Commons licence, unless indicated otherwise in a credit line to the material. If material is not included in the article's Creative Commons licence and your intended use is not permitted by statutory regulation or exceeds the permitted use, you will need to obtain permission directly from the copyright holder. To view a copy of this licence, visit http://creativecommons.org/licenses/by/4.0/.

\section{References}

1. Lichtenberg FR (2013) The impact of therapeutic procedure innovation on hospital patient longevity: evidence from Western Australia, 2000-2007. Soc Sci Med 77:50-59

2. Dorsey ER, De JR, Thompson JP, Reminick JI, Thai A, WhiteStellato Z et al (2010) Funding of US biomedical research, 20032008., Financial Anatomy of Biomedical Research, 2003-2008. JAMA 303(137):137-143

3. Sampat BN, Lichtenberg FR (2011) What are the respective roles of the public and private sectors in pharmaceutical innovation? Health Aff 30:332-339

4. Briesacher BA, Andrade SE, Fouayzi H, Chan KA (2008) Comparison of drug adherence rates among patients with seven different medical conditions. Pharmacotherapy: The Journal of Human Pharmacology and Drug Therapy 28:437-443

5. Sokol MC, McGuigan KA, Verbrugge RR, Epstein RS (2005) Impact of medication adherence on hospitalization risk and healthcare cost. Med Care 43:521-530

6. Cramer JA, Benedict á, Muszbek N, Keskinaslan A, Khan ZM (2007) The significance of compliance and persistence in the treatment of diabetes, hypertension and dyslipidaemia: a review: 
Compliance in cardiovascular disease. International Journal of Clinical Practice 62:76-87

7. Osterberg L, Blaschke T (2005) Adherence to medication. N Engl J Med 353:487-497

8. IMS Institute for Healthcare Informatics. Avoidable Costs in U.S. Healthcare - The \$200 Billion Opportunity from Using Medicines More Responsibly. 2013; Available from: https://www.imshealth. $\mathrm{com} /$ en/thought-leadership/webinar-library/avoidable-costs-in-ushealthcare-200-billion-opportunity

9. Gallivan S, Pagel C, Utley M, Dean Franklin B, Taxis K, Barber N (2008) A technical note concerning non-adherence to drug therapy: exact expressions for the mean and variance of drug concentration. Health Care Manage Sci 11:296-301

10. Smith D, Pagel C, Utley M, Gallivan S (2008) Quantifying the impact of non-adherence to drug therapy: a technical note concerning an application of a branch and bound algorithm. Health Care Manage Sci. 11:302-305

11. Nieuwlaat R, Wilczynski N, Navarro T, Hobson N, Jeffery R, Keepanasseril A et al (2014) Interventions for enhancing medication adherence. Cochrane Database Syst Rev 11:CD000011

12. Sapkota S, Brien J, Greenfield J, Aslani P. A Systematic Review of Interventions Addressing Adherence to Anti-Diabetic Medications in Patients with Type 2 Diabetes - Impact on Adherence. PLoS One [Internet]. 2015 [cited 2015 Aug 27];10. Available from: http://www.ncbi.nlm.nih.gov/pmc/articles/PMC4339210/

13. Hughes DA, Bagust A, Haycox A, Walley T (2001) The impact of non-compliance on the cost-effectiveness of pharmaceuticals: a review of the literature. Health Econ 10:601-615

14. Viswanathan M, Golin C, Jones C, Ashok M, Blalock S, Wines R, et al. 4. Medication Adherence Interventions: Comparative Effectiveness: Closing the Quality Gap: Revisiting the State of the Science. AHRQ Publication No 12-E010. 2012;

15. Ito K, Shrank WH, Avorn J, Patrick AR, Brennan TA, Antman EM et al (2012 Dec) Comparative cost-effectiveness of interventions to improve medication adherence after myocardial infarction. Health Services Research 47:2097+

16. Chapman RH, Ferrufino CP, Kowal SL, Classi P, Roberts CS (2009) The cost and effectiveness of adherence-improving interventions for antihypertensive and lipid-lowering drugs*: relative cost and effectiveness of adherence interventions. Int J Clin Pract 64:169-181

17. Chernew ME, Shah MR, Wegh A, Rosenberg SN, Juster IA, Rosen AB, Sokol MC, Yu-Isenberg K, Fendrick AM (2008) Impact of decreasing copayments on medication adherence within a disease management environment. Health Aff 27:103-112

18. Sacks NC, Burgess JF, Cabral HJ, McDonnell ME, Pizer SD (2015) The effects of cost sharing on adherence to medications prescribed for concurrent use: do definitions matter? J Manag Care Spec Pharm 21:678-687

19. Sacks NC, Burgess JF, Cabral HJ, Pizer SD, McDonnell ME (2013) Cost sharing and decreased branded Oral anti-diabetic medication adherence among elderly part D Medicare beneficiaries. J Gen Intern Med 28:876-885

20. Jung K, Feldman R, McBean AM (2014) Nonlinear pricing in drug benefits and medication use: the case of statin compliance in Medicare part D. Health Serv Res 49:910-928

21. Gibson TB, Wang S, Kelly E, Brown C, Turner C, Frech-Tamas F, Doyle J, Mauceri E (2011) A value-based insurance design program at a large company boosted medication adherence for employees with chronic illnesses. Health Aff 30:109-117

22. Briesacher BA, Andrade SE, Fouayzi H, Chan KA (2009) Medication adherence and the use of generic drug therapies. Am J Manag Care 15:450-456

23. Seabury SA, Lakdawalla DN, Dougherty JS, Sullivan J, Goldman DP (2015) Medication adherence and measures of health plan quality. Am J Manag Care 21:e379-e389
24. Lau DT, Nau DP (2004) Oral antihyperglycemic medication nonadherence and subsequent hospitalization among individuals with type 2 diabetes. Diabetes Care 27:2149-2153

25. Cullen BA, McGinty EE, Zhang Y, SC dR, Steinwachs DM, Guallar E et al (2013) Guideline-concordant antipsychotic use and mortality in schizophrenia. Schizophr Bull 39:1159-1168

26. Egede LE, Lynch CP, Gebregziabher M, Hunt KJ, Echols C, Gilbert GE, Mauldin PD (2013) Differential impact of longitudinal medication non-adherence on mortality by race/ethnicity among veterans with diabetes. J Gen Intern Med 28:208-215

27. Roebuck MC, Liberman JN, Gemmill-Toyama M, Brennan TA (2011) Medication adherence leads to lower health care use and costs despite increased drug spending. Health Aff 30:91-99

28. Ho PM, Bryson CL, Rumsfeld JS (2009) Medication adherence: its importance in cardiovascular outcomes. Circulation. 119:30283035

29. Lichtenberg DFR (2012) Contribution of pharmaceutical innovation to longevity growth in Germany and France, 2001-7. PharmacoEconomics. 30:197-211

30. Lichtenberg FR (2014) The impact of pharmaceutical innovation on disability days and the use of medical services in the United States, 1997-2010. J Hum Cap 8:432-480

31. Bresnahan TF, Gordon RJ (eds) (1997) The economics of new goods. University of Chicago Press, Chicago

32. Grossman GM, Helpman E (1991) Quality ladders in the theory of growth. Rev Econ Stud 58:43-61

33. Aghion P, Howitt P. Chapter 2 Growth with Quality-Improving Innovations: An Integrated Framework. In: Aghion P, Durlauf SN, editors. Handbook of Economic Growth [Internet]. Elsevier; 2005 [cited 2020 Jan 28]. p. 67-110. Available from: http://www. sciencedirect.com/science/article/pii/S1574068405010026

34. Solow R (1960) Investment and technological Progress. In: Arrow K, Karlin S, Suppes P (eds) Mathematical methods in the social sciences, 1959. Stanford University Press, Stanford, Calif

35. Jovanovic B, Yatsenko Y (2012) Investment in vintage capital. J Econ Theory 147:551-569

36. Greenwood J, Hercowitz Z, Krusell P (1997) Long-run implications of investment-specific technological change. Am Econ Rev:342362

37. Merrian Webster. Definition of VINTAGE [Internet]. 2017 [cited 2017 Feb 21]. Available from: https://www.merriam-webster.com/ dictionary/vintage

38. Saini SD, Schoenfeld P, Kaulback K, Dubinsky MC (2009) Effect of medication dosing frequency on adherence in chronic diseases. Am J Manag Care 15:e22-e33

39. Pease AM, Krumholz HM, Downing NS, Aminawung JA, Shah ND, Ross JS (2017) Postapproval studies of drugs initially approved by the FDA on the basis of limited evidence: systematic review. BMJ. 357:j1680

40. Wieseler B, McGauran N, Kaiser T. New drugs: where did we go wrong and what can we do better? BMJ [Internet]. 2019 [cited 2020 Jan 20];366. Available from: https://www.bmj.com/content/366/ bmj.14340

41. Gyawali B, Hey SP, Kesselheim AS (2019) Assessment of the clinical benefit of Cancer drugs receiving accelerated approval. JAMA Intern Med 179:906-913

42. Lichtenberg FR (2018) The impact of new drug launches on LIFEyears lost in 2015 from 19 types of cancer in 36 countries. Journal of Demographic Economics 84:309-354

43. Lichtenberg FR. How cost-effective are new cancer drugs in the U.S.? Expert Review of Pharmacoeconomics \& Outcomes Research. 2020;0:1-17

44. Lichtenberg FR (2019) How many life-years have new drugs saved? A three-way fixed-effects analysis of 66 diseases in 27 countries, 2000-2013. Int Health 11:403-416 
45. Lichtenberg FR (2019) The impact of access to prescription drugs on disability in eleven European countries. Disability and Health Journal 12:375-386

46. Lichtenberg FR (2014) Pharmaceutical innovation and longevity growth in 30 developing and high-income countries, 2000-2009. Health Policy and Technology 3:36-58

47. Pappu R, Quester PG (2016) How does brand innovativeness affect brand loyalty? Eur J Mark 50:2-28

48. Yoo B, Donthu N, Lee S (2000) An examination of selected marketing mix elements and brand equity. J of the Acad Mark Sci 28: 195-211

49. Olsen SO (2002) Comparative evaluation and the relationship between quality, satisfaction, and repurchase loyalty. J Acad Mark Sci 30:240-249

50. Kirkman MS, Rowan-Martin MT, Levin R, Fonseca VA, Schmittdiel JA, Herman WH et al (2015) Determinants of adherence to diabetes medications: findings from a large pharmacy claims database. Dia Care 38:604-609

51. Schmittdiel JA, Nichols GA, Dyer W, Steiner JF, Karter AJ, Raebel MA (2015) Health care system-level factors associated with performance on Medicare STAR adherence metrics in a large, integrated delivery system. Med Care 53:332-337

52. Stuart B, Dai M, Xu J (2015) E Loh F-H, S Dougherty J. does good medication adherence really save payers money? Med Care 53: $517-523$

53. Mittal V, Kamakura WA (2001) Satisfaction, repurchase intent, and repurchase behavior: investigating the moderating effect of customer characteristics. J Mark Res 38:131-142

54. Cooil B, Keiningham TL, Aksoy L, Hsu M (2007) A longitudinal analysis of customer satisfaction and share of wallet: investigating the moderating effect of customer characteristics. J Mark 71:67-83

55. Brown JD, Doshi PA, Talbert JC (2017) Utilization of free medication samples in the United States in a nationally representative sample: 2009-2013. Res Soc Adm Pharm 13:193-200

56. Alexander GC, Zhang J, Basu A (2008) Characteristics of Patients Receiving Pharmaceutical Samples and Association Between Sample Receipt and Out-of-Pocket Prescription Costs. Medical Care 46:394-402

57. Truven Health Analytics. RED BOOK [Internet]. 2016 [cited 2016 Feb 4]. Available from: http://sites.truvenhealth.com/redbook/ about/

58. Food and Drug Administration. Drugs@FDA: FDA Approved Drug Products [Internet]. 2016 [cited 2016 Feb 4]. Available from: https://www.accessdata.fda.gov/scripts/cder/drugsatfda/

59. Régnier S (2013) What is the value of 'me-too' drugs? Health Care Manag Sci 16:300-313

60. Food and Drug Administration. Drug and Biologic Approval and IND Activity Reports [Internet]. 2016 [cited 2016 Feb 2]. Available from: http://www.fda.gov/Drugs/DevelopmentApprovalProcess/ H o w D r u g a r e D e v e lopedand A p proved/ DrugandBiologicApprovalReports/default.htm

61. Iizuka T (2004) What explains the use of direct-to-consumer advertising of prescription drugs? J Ind Econ 52:349-379

62. Wosinska M (2005) Direct-to-consumer advertising and drug therapy compliance. J Mark Res 42:323-332

63. Atella V, Belotti F, Depalo D (2017) Drug therapy adherence and health outcomes in the presence of physician and patient unobserved heterogeneity. Health Econ 26:106-126

64. Shrank WH, Patrick AR, Brookhart MA (2011) Healthy user and related biases in observational studies of preventive interventions: a primer for physicians. J Gen Intern Med 26:546-550
65. Krueger KP, Berger BA, Felkey B (2005) Medication adherence and persistence: a comprehensive review. Adv Therapy 22:313356

66. Steiner JF (2012) Rethinking adherence. Ann Intern Med 157:580 585

67. LaFleur J, Nelson RE, Sauer BC, Nebeker JR (2011) Overestimation of the effects of adherence on outcomes: a case study in healthy user bias and hypertension. Heart. 97:1862-1869

68. Greenhalgh T, Robert G, Macfarlane F, Bate P, Kyriakidou O (2004) Diffusion of innovations in service organizations: systematic review and recommendations. Milbank Q 82:581-629

69. Mathes T, Jaschinski T, Pieper D (2014) Adherence influencing factors - a systematic review of systematic reviews. Archives of Public Health 72:37

70. Wooldridge JM. Introductory econometrics: a modern approach. 5th ed. [Mason, Ohio] [u.a.]: South-Western Cengage Learning; 2013

71. Choudhry NK, Avorn J, Glynn RJ, Antman EM, Schneeweiss S, Toscano M, Reisman L, Fernandes J, Spettell C, Lee JL, Levin R, Brennan T, Shrank WH (2011) Full coverage for preventive medications after myocardial infarction. N Engl J Med 365:2088-2097

72. Donohue JM, Berndt ER (2004) Effects of direct-to-consumer advertising on medication choice: the case of antidepressants. J Public Policy Mark 23:115-127

73. Avery RJ, Eisenberg MD, Simon KI (2012) The impact of direct-toconsumer television and magazine advertising on antidepressant use. J Health Econ 31:705-718

74. Cardon JH, Showalter MH (2015) The effects of direct-toconsumer advertising of pharmaceuticals on adherence. Appl Econ 47:5432-5444

75. Mizik N, Jacobson R (2004) Are physicians "easy Marks"? Quantifying the effects of detailing and sampling on new prescriptions. Manag Sci 50:1704-1715

76. Kaplan C, Zhang Y (2014) The January effect: medication Reinitiation among Medicare part D beneficiaries. Health Econ 23:1287-1300

77. Lichtenberg FR (2009) Have newer cardiovascular drugs reduced hospitalization? Evidence from longitudinal country-level data on 20 OECD countries, 1995-2003. Health Econ 18:519-534

78. Khunti K, Seidu S, Kunutsor S, Davies M (2017) Association between adherence to pharmacotherapy and outcomes in type 2 diabetes: a meta-analysis. Diabetes Care 40:1588-1596

79. Bradford WD, Kleit AN (2015) Impact of FDA actions, DTCA, and public information on the market for pain medication. Health Econ 24:859-875

80. Genberg BL, Rogers WH, Lee Y, Qato DM, Dore DD, Hutchins DS, Brennan T, Matlin OS, Wilson IB (2016) Prescriber and pharmacy variation in patient adherence to five medication classes measured using implementation during persistent episodes. Pharmacoepidemiol Drug Saf 25:790-797

81. Seabury SA, Dougherty S, Sullivan J. Medication Adherence as a Measure of the Quality of Care Provided by Physicians [Internet]. Rochester, NY: Social Science Research Network; 2017 Nov. Report No.: ID 3064247. Available from: https://papers.ssrn.com/ abstract $=3064247$

Publisher's note Springer Nature remains neutral with regard to jurisdictional claims in published maps and institutional affiliations. 